\title{
Nitrous Oxide-dependent Iron-catalyzed Coupling Reactions of Grignard Reagents
}

\author{
Peter Döhlert, Maik Weidauer, and Stephan Enthaler*
}

\begin{abstract}
The formation of carbon-carbon bonds is one of the fundamental transformations in chemistry. In this regard the application of palladium-based catalysts has been extensively investigated during recent years, but nowadays research focuses on iron catalysis, due to sustainability, costs and toxicity issues; hence numerous examples for iron-catalyzed cross-coupling reactions have been established, based on the coupling of electrophiles $\left(R^{1}-X, X=\right.$ halide) with nucleophiles $\left(R^{2}-M g X\right)$. Only a small number of protocols deals with the iron-catalyzed oxidative coupling of nucleophiles $\left(R^{1}-M g X+R^{2}-M g X\right)$ with the aid of oxidants (1,2-dihaloethanes). However, some issues arise with these oxidants; hence more recently the potential of the industrial waste product nitrous oxide $\left(\mathrm{N}_{2} \mathrm{O}\right)$ was investigated, because the unproblematic side product $\mathrm{N}_{2}$ is formed. Based on that, we demonstrate the catalytic potential of easily accessible iron complexes in the oxidative coupling of Grignard reagents. Importantly, nitrous oxide was essential to obtain yields up to $>99 \%$ at mild conditions (e.g. $1 \mathrm{~atm}$, ambient temperature) and low catalyst loadings $(0.1 \mathrm{~mol} \%)$ Excellent catalyst performance is realized with turnover numbers of up to 1000 and turnover frequencies of up to $12000 \mathrm{~h}^{-1}$. Moreover, a good functional group tolerance is observed (e.g. amide, ester, nitrile, alkene, alkyne). Afterwards the reaction of different Grignard reagents revealed interesting results with respect to the selectivity of cross-coupling product formation.
\end{abstract}

Keywords: Grignard reagents · Iron catalysts · Nitrous oxide

\section{Introduction}

The formation of carbon-carbon bonds is one of the fundamental transformations in chemistry to produce pharmaceuticals, bulk and fine chemicals, agrochemicals, polymers etc. ${ }^{[1]}$ In this regard, transitionmetal catalyzed coupling reactions offer a versatile strategy and nowadays it is an established methodology and success has been proven in countless synthetic methodologies. ${ }^{[2]}$ However, due to an increasing demand and modification of regulations (e.g. sustainability and environmental issues) novel protocols for $\mathrm{C}-\mathrm{C}$ bond formations are still of interest and a challenging task for industrial and academic research. ${ }^{[3]}$ For instance numerous impressive processes have been reported for palladium catalysis, but some issues arise from its low abundance in the earth crust $(\sim 0.006$

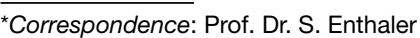
Technische Universität Berlin Institute of Chemistry: Cluster of Excellence 'Unifying Concepts in Catalysis' Straße des 17. Juni 115/C2 D-10623 Berlin, Germany E-Mail: stephan.enthaler@tu-berlin.de
}

ppm) and therefore high costs $(\sim 1460 €$ per mole), and the high toxicity of this metal creates problems with respect to pharmaceutical applications. ${ }^{[4,5]}$ Based on these negative issues, a current trend in catalysis is the development of more environmentally benign and sustainable alternatives. ${ }^{[6]}$ In particular replacement with cheaper and low toxic iron catalysts is envisaged (4th most abundant element of earth's crust, <0.01 €/mol). Indeed, numerous iron-catalyzed cross-coupling reactions have been reported so far, mainly based on the coupling of an electrophile (e.g. $\mathrm{C}\left(\mathrm{sp}^{2}, \mathrm{sp}^{3}\right.$ hybridization)-halogen) with a nucleophile (e.g. $\mathrm{C}\left(\mathrm{sp}^{2}, \mathrm{sp}^{3}\right.$ hybridization)Mg-halogen) (Fig. 1). ${ }^{[7]}$ Moreover, a small number of protocols described the ironcatalyzed coupling of two nucleophiles (e.g. Grignard reagents), on the one hand the oxidative homo-coupling and on the other hand the oxidative cross-coupling. ${ }^{[8]}$ Importantly, mainly 1,2-dihaloethanes were applied as the oxidant to access the coupling products in reasonable yields. However, some sustainability issues arise from the application of 1,2-dihaloethanes, e.g. origin from fossil resources, formation of waste, reactivity of the side product. Recently, the group of Severin reported an alternative iron-catalyzed oxidative homocoupling approach by replacing 1,2-dihaloethanes with the industrial waste product nitrous oxide $\left(\mathrm{N}_{2} \mathrm{O}\right)$, forming as side product unproblematic $\mathrm{N}_{2}{ }^{[9]}$ Interestingly, anthropogenic $\mathrm{N}_{2} \mathrm{O}$ is produced as waste product, e.g. in industrial Nylon produc- tion, and is a greenhouse gas with a warming potential 300 times greater than $\mathrm{CO}_{2} \cdot{ }^{[10]}$ The industrial emission is mainly reduced by the implementation of decomposition protocols. ${ }^{[11]}$ Hence the application of $\mathrm{N}_{2} \mathrm{O}$ as oxidant can be an option to reduce the amounts of waste and add value to a greener, sustainable and environmentally friendly chemistry. More recently, we reported the catalytic application of a trispyrrole iron(II) complex in coupling reactions using $\mathrm{N}_{2} \mathrm{O}$ as oxidant. ${ }^{[12]}$ On the one hand activity was observed in the homo-coupling of $\mathrm{sp}^{2}$ hybridized Grignard reagents and on the other hand cross-coupling of different $\mathrm{sp}^{2}$ hybridized Grignard reagents were studied. However, low selectivity for the cross-coupling product was revealed and significant amounts of the homo-coupling products are formed (Fig. 1). Based on this initial work we became interested in the improvement of the catalyst activity and the improvement of the selectivity towards the cross- coupling products.

\section{Results and Discussion}

The iron complexes $\mathbf{1 a}-\mathbf{1 d}$ and $\mathbf{2 a}, \mathbf{2 b}$ were synthesized in accordance to recently reported procedures. In more detail, the reaction of iron(II) chloride with the corresponding substituted imidazole or pyridine and subsequent addition of molecular oxygen allowed access to the complexes. ${ }^{[13-15]}$ With this selection of precatalysts in hand we evaluated the potential in the 


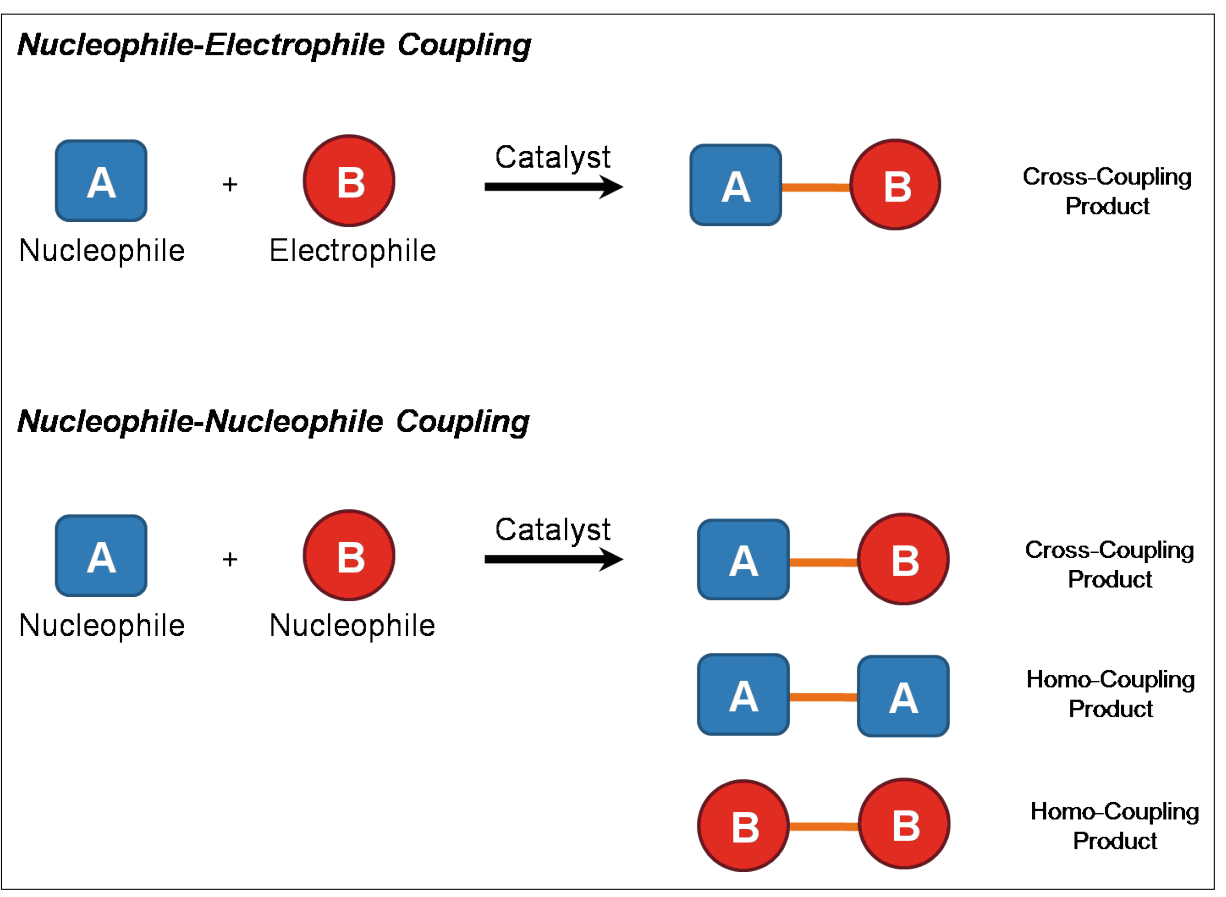

Fig. 1. Iron-catalyzed cross-coupling approaches. to the Grignard reagent 3 and complex 1d $(0.01 \mathrm{~mol} \%)$ under an atmosphere of $\mathrm{N}_{2} \mathrm{O}$. For instance in the presence of different organic acid derivatives (amide, ester, nitriles) complex 1d successfully performed the homo-coupling of $\mathbf{3}$ with somewhat reduced activity, e.g. for nitrile 7 only $64 \%$ yield of 4 were realized within $5 \mathrm{~min}$ (Table 2, entry 3 ), while with the ester-containing additive 6 full conversion with an excellent selectivity was obtained (Table 2, entry 2). Importantly, no conversion of the functional group was monitored (Table 2, entries 1-3). In contrast, the addition of an additive containing a ketone or sulfoxide function revealed the transformation of the functional group (Table 2, entries 4 and 5). In the case of addition of bromobenzene $\mathbf{1 0}$ the homo-coupling of the Grignard reaction was exclusively performed by complex $\mathbf{1 d}$, while the cross-coupling product was not observed (Table 2, entry 6). Interestingly, this result can be attractive for controlling the reaction outcome of reaction sequences, e.g. selective nucleophile-nucleophile iron-catalyzed homo-coupling reaction of 4-methoxyphenylmagnesium bromide 3 to produce 4,4'-dimethoxybiphenyl 4 (Table 1). ${ }^{[16]}$ Initially, the reaction was performed under a nitrogen atmosphere with catalytic amounts $(0.1 \mathrm{~mol} \%)$ of complex $1 d$ at room temperature, but no product formation was observed (Table 1, entry 1). In contrast, changing the atmosphere to molecular oxygen revealed the formation of $64 \%$ coupling product after $5 \mathrm{~min}$ (Table 1 , entry 2), while with nitrous oxide the yield of $\mathbf{4}$ was improved towards $95 \%$ (Table 1, entry 3). Interestingly, a significant gas evolution and heat production was noticed in the presence of $\mathrm{N}_{2} \mathrm{O}$. A similar reactivity was observed in the presence of 0.05 mol\% precatalyst 1d, which corresponds to a turnover number of 950 and a turnover frequency ${ }^{[17]}$ of $11400 \mathrm{~h}^{-1}$ (Table 1 , entry $6)$. In contrast to the work of Severin and co-workers ${ }^{[9]}$ with catalytic amounts of metal salts (reaction time: $1 \mathrm{~h}$ ) and our earlier investigation with a trispyrrole iron(II) complex ${ }^{[12]}$ (reaction time: $24 \mathrm{~h}$ ) excellent yields $(>90 \%)$ were obtained within short reaction times ( $5 \mathrm{~min}$ ). Noteworthy, applying complexes $\mathbf{1 a - 1 c}$ and $\mathbf{2 a}$ as precatalysts similar yields (93-97\%) were monitored for product $\mathbf{4}$ after 5 min (Table 1, entries 7-10), while with complex $\mathbf{2 b}$ no product formation was detected, due to low solubility (Table 1, entry 11).

Afterwards the functional group tolerance of the iron-catalyzed oxidative homocoupling protocol was studied (Table 2). Based on that, an intramolecular screening protocol was applied. ${ }^{[18]}$ In more detail, stoichiometric amounts of an additive containing a functional group was added
Table 1. Nitrous oxide dependent iron-catalyzed oxidative homo-coupling of aryl Grignard reagent 3.

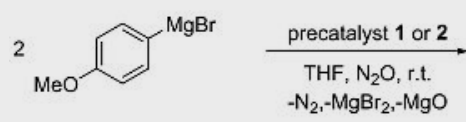

3

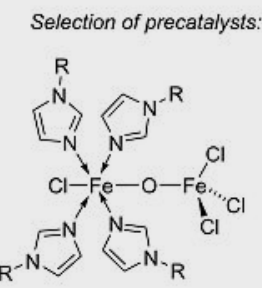

1a: $R=M e$

1b: $R=t-B u$

1c: $\mathrm{R}=2,4,6-\mathrm{Me}_{3} \mathrm{C}_{6} \mathrm{H}_{2}$

1d: $R=4-\mathrm{MeOC}_{6} \mathrm{H}_{4}$

\section{Entry $^{\mathrm{a}}$ Precatalyst Catalyst loading [mol\%]}

\begin{tabular}{|c|c|}
\hline 1 & $1 d$ \\
\hline 2 & $1 d$ \\
\hline 3 & $1 d$ \\
\hline 4 & $1 d$ \\
\hline 5 & $1 d$ \\
\hline 6 & $1 d$ \\
\hline 7 & $1 a$ \\
\hline 8 & $1 b$ \\
\hline 9 & $1 c$ \\
\hline 10 & $\mathbf{1 a}$ \\
\hline 11 & $\mathbf{2 b}$ \\
\hline
\end{tabular}

0.1

0.1

0.1

0.1

0.1

0.05

0.1

0.1

0.1

0.1

0.1
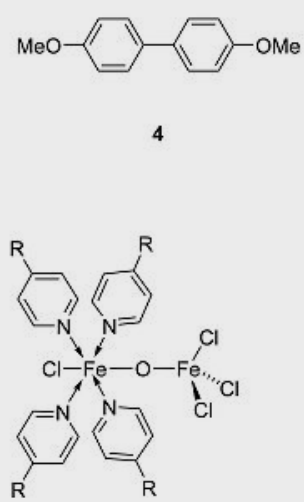

2a: $\mathrm{R}=\mathrm{H}$

2b: $\mathrm{R}=\mathrm{NMe}_{2}$

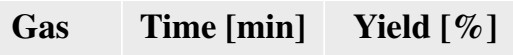

$\mathrm{N}_{2}$

$\mathrm{O}_{2}$

$$
5
$$$$
5
$$

$<1$

$\mathrm{N}_{2} \mathrm{O}$

$$
5
$$

64

$\mathrm{N}_{2} \mathrm{O}$

10

95

$\mathrm{N}_{2} \mathrm{O}$

97

97

$\mathrm{N}_{2} \mathrm{O}$

30

95

$\mathrm{N}_{2} \mathrm{O}$

93

$\mathrm{N}_{2} \mathrm{O} \quad 5$

$\mathrm{N}_{2} \mathrm{O} \quad 5$

$\mathrm{N}_{2} \mathrm{O} \quad 5 \quad 96$

$\mathrm{N}_{2} \mathrm{O} \quad 5 \quad<1^{\mathrm{b}}$

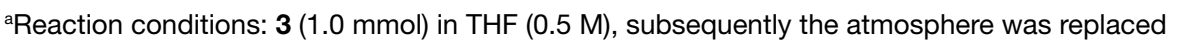
and a solution of $1(0.001 \mathrm{mmol})$ in THF $(0.1 \mathrm{~mL})$ was added. The mixture was stirred for $5-30 \mathrm{~min}$ at r.t. Yields were determined by GC-MS analysis with $\mathrm{n}$-dodecane as internal standard. ${ }^{\mathrm{b}} \mathrm{Poor}$ solubility of $\mathbf{2 b}$. 
Table 2. Nitrous oxide dependent iron-catalyzed oxidative homocoupling - intermolecular reaction evaluation.<smiles>CCNc1ccc(OC)cc1</smiles>

3

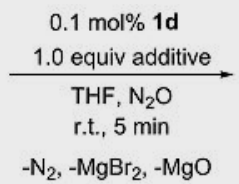

$-\mathrm{N}_{2},-\mathrm{MgBr}_{2},-\mathrm{MgO}$
5

2<smiles>COC(=O)c1ccc(C#N)cc1</smiles>

3<smiles>CN(C)c1ccc(C#N)cc1</smiles>

4<smiles>CNc1ccc(C(C)=O)cc1</smiles>

5

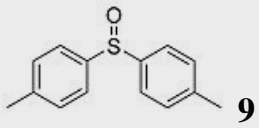

6<smiles>Brc1ccccc1</smiles>

10

7

8

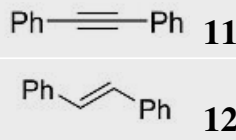

6

7
Yield [\%] 4

87

4

Stability

Yes

$>99$

Yes

83

Yes

58

Yes

71

Yes

a Reaction conditions: $3(1.0 \mathrm{mmol})$ in THF (0.5 M), additive $(1.0 \mathrm{mmol})$, subsequently the atmosphere was replaced and a solution of 1 a $(0.001$ $\mathrm{mmol})$ in THF $(0.1 \mathrm{~mL})$ was added. The mixture was stirred for $5 \mathrm{~min}$ at r.t. Yields were determined by GC-MS analysis with n-dodecane as internal standard.

coupling in the presence of an electrophile under $\mathrm{N}_{2} \mathrm{O}$ and nucleophile-electrophile coupling under $\mathrm{N}_{2}$.

Next the potential of complex $\mathbf{1 d}$ in the oxidative homo-coupling of different Grignard compounds was evaluated (Table 3 , entries 1-6). In more detail, an excellent performance (yield: $>99 \%$ ) was observed for the conversion of Grignard reagent $\mathbf{1 3}$ containing a thioether function, which has been reported as a useful leaving group for $\mathrm{C}-\mathrm{C}$ bond formations (Table 3, entry 2). ${ }^{[19]}$ Moreover, the sterically demanding mesityl Grignard reagent $\mathbf{1 5}$ was applied as substrate (Table 3, entry 4). Unfortunately, no coupling product was observed, probably due to steric reasons. A similar result was obtained for the radical clock substrate 16 (Table 3, entry 5). In addition to the coupling of $\mathrm{sp}^{2}-\mathrm{sp}^{2}$ hybridized Grignard reagents the coupling of $\mathrm{sp}^{3}-\mathrm{sp}^{3}$ hybridized Grignard reagents was investigated, resulting in a somewhat lower yield of $56 \%$ for 17 (Table 3, entry 6).

After having established the oxidative homo-coupling of Grignard reagents with $\mathrm{N}_{2} \mathrm{O}$ we focused on the transfer of the protocol towards the oxidative cross-coupling of two different Grignard reagents (Table 3 , entries 7-12). Initially, in the presence of complex $1 \mathbf{d}(0.1 \mathrm{~mol} \%)$ and $\mathrm{N}_{2} \mathrm{O}$ equal amounts of $3(0.5 \mathrm{mmol})$ and $14(0.5$ mmol) were reacted. Interestingly, after 5 minutes a mixture of three products was detected (Table 3, entry 7). On the one hand the homo-coupling products of $\mathbf{3}$ (5\% of the product mixture) and $14(22 \%)$ and on the other hand the cross-coupling product $18(73 \%)$ as the major component. Importantly, the amount of the cross-coupling product 18 surpasses the statistic distribution, demonstrating the control of the selectivity by the catalyst. A similar result was obtained when replacing phenyl magnesium bromide by phenyl magnesium chloride (Table 3, entry 8). Moreover, an increased yield ( $84 \%$ of the product mixture) for the cross-coupling product was noticed for the reaction of $\mathbf{3}$ and $\mathbf{1 3}$ (Table 3 , entry 9). Next the reaction of $\mathrm{sp}^{2}$ hybridized Grignard reagents with $\mathrm{sp}^{3}$ hybridized Grignard reagents was studied. For instance cyclohexyl magnesium bromide 21 was reacted with 3 in the presence of $1 d$ and $\mathrm{N}_{2} \mathrm{O}$ (Table 3, entry 10). As major pathway the homo-coupling of $\mathbf{2 1}$ was observed (61\% of the product mixture), while the cross-coupling product was observed in $37 \%$. In contrast to that, changing the $\mathrm{sp}^{3}$ hybridized carbon function from secondary to primary improved the yield of the cross-coupling product (Table 3, entry 11). Finally, the cross-coupling of $\mathrm{sp}^{3}$ hybridized Grignard reagents was investigated (Table 3 , entry 12 ), revealing the crosscoupling product as major component of the product mixture.

\section{Summary}

In summary we have demonstrated the catalytic potential of simple and easily accessible iron complexes in the oxidative coupling of Grignard reagents. Importantly, to force the reaction, addition of nitrous oxide was necessary to obtain yields up to $>99 \%$ at mild conditions (e.g. $1 \mathrm{~atm}$, ambient temperature) and low catalyst loadings $(0.1 \mathrm{~mol} \%)$ within short reaction times (5 min). Interestingly, excellent catalyst performance was realized with turnover numbers of up to 1000 and turnover frequencies of up to $12000 \mathrm{~h}^{-1}$.[17] Moreover, an intramolecular screening protocol with functional group containing additives revealed in most cases excellent selectivity for the oxidative homocoupling (e.g. amide, ester, nitrile, alkene, alkyne). Afterwards the reaction of different Grignard reagents showed interesting results with respect to the selectivity of the formation of the cross-coupling product.

\section{Acknowledgements}

Financial support from the Cluster of Excellence "Unifying Concepts in Catalysis" (funded by the Deutsche Forschungsgemeinschaft and administered by the Technische Universität Berlin) is gratefully acknowledged.

Received: April 16, 2015 
Table 3. Iron-catalyzed oxidative homo-coupling and hetero-coupling of aryl Grignard compounds.

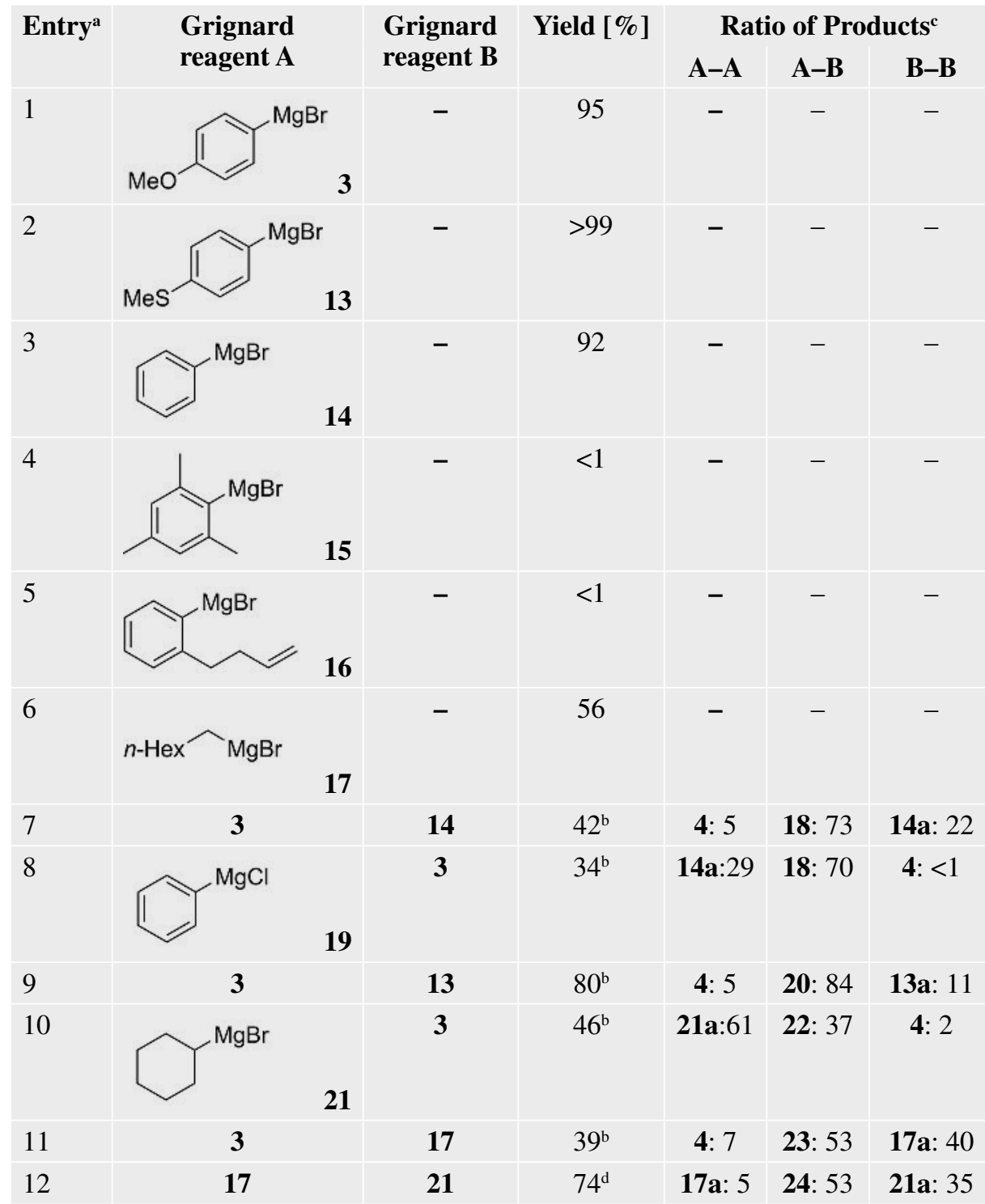

aReaction conditions: Grignard reagent $(1.0 \mathrm{mmol}$ for homo coupling) or Grignard reagent A (0.5 $\mathrm{mmol})$ and Grignard reagent B $(0.5 \mathrm{mmol})$ (for hetero coupling) in THF $(0.5 \mathrm{M})$, subsequently the atmosphere was replaced and a solution of $1 \mathbf{a}(0.001 \mathrm{mmol})$ in THF $(0.1 \mathrm{~mL})$ was added. The mixture was stirred for $5 \mathrm{~min}$ at r.t. Yields/conversions were determined by GC-MS analysis applying $\mathrm{n}$-dodecane as internal standard. ${ }^{b}$ Value corresponds to the conversion of compound 3. ${ }^{\mathrm{C}}$ Ratio of the homo-coupling products $\mathrm{A}-\mathrm{A}, \mathrm{B}-\mathrm{B}$ and the hetero-coupling product $\mathrm{A}-\mathrm{B}$ determined by GC-MS analysis. 'Value corresponds to the conversion of compound 17.

[1] See for instance: 'Metal-Catalyzed CrossCoupling Reactions and More', Eds. A. de Meijere, S. Bräse, M. Oestreich, 2014, WileyVCH Weinheim.

[2] M. Beller, Chem. Soc. Rev. 2011, 40, 4891.

[3] P. T. Anastas, ChemSusChem 2009, 2, 391.

[4] 'List of Periodic Table Elements Sorted by Abundance in Earth's crust', Israel Science and Technology Homepage. Retrieved 2007-04-15.

[5] 'Platinum Today', www.platinum.matthey.com, accessed 15 September 2014.

[6] See for instance: a) P. T. Anastas, M. M. Kirchhoff, Acc. Chem. Res. 2002, 35, 686; b) J. L. Tucker, Org. Process Res. Dev. 2010, 14, 328; c) R. Dach, J. J. Song, F. Roschangar, W. Samstag, C. H. Senanayake, Org. Process Res. Dev. 2012, 16, 1697.
[7] See for instance: I. Bauer, H.-J. Knölker, Chem. Rev. 2015, dx.doi.org/10.1021/cr500425u and references therein.

[8] See for instance: a) G. Cahiez, C. Chaboche, F. Mahuteau-Betzer, M. Ahr, Org. Lett. 2005, 7, 1943; b) T. Nagano, T. Hayashi, Org. Lett. 2005, 7, 491; c) G. Cahiez, A. Moyeux, J. Buendia, C. Duplais, J. Am. Chem. Soc. 2007, 129, 13788; d) W. Liu, A. Lei, Tetrahedron Lett. 2008, 49, 610 ; e) T. Itoh, K. Kude, A. Ishioka, S. Hayase, M. Kawatsura, ECS Trans. 2008, 13, 47; f) G. Cahiez, L. Foulgoc, A. Moyeux, Angew. Chem., Int. Ed. 2009, 48, 2969; g) W. Yang, J. Zhou, B. Wang, H. Ren, Chem.-Eur. J. 2011, 17, 13665.

[9] G. Kiefer, L. Jeanbourquin, K. Severin, Angew. Chem. Int. Ed. 2013, 52, 6302.

[10] See for instance: a) J. C. Kramlich, W. P. Linak, Prog. Energ. Combust. Sci. 1994, 20, 149; b)
A. Mosier, C. Kroeze, C. Nevison, O. Oenema, S. Seitzinger, O. van Cleemput, Nutr. Cycle. Agroecosys. 1998, 52, 225.

[11] A. Shimizu, K. Tanaka, M. Fujimori, Chemosphere - Global Change Science 22000, 425.

[12] M. Weidauer, E. Irran, S. Enthaler, Inorg. Chem. Commun. 2015, 54, 1 .

[13] K. Schröder, S. Enthaler, B. Bitterlich, T. Schulz, A. Spannenberg, M. K. Tse, K. Junge, M. Beller, Chem.-Eur. J. 2009, 15, 5471.

[14] P. Döhlert, E. Irran, R. Kretschmer, S. Enthaler, Inorg. Chem. Commun. 2015, 51, 4.

[15] M. Haberberger, K. Mayer, E. Irran, R. Kretschmer, S. Enthaler, submitted.

[16] General procedure for iron-catalyzed coupling of aryl Grignard reagents: A Schlenk tube was charged with the corresponding Grignard reagent $(1.0 \mathrm{mmol}, 0.5 \mathrm{M}$ in THF, $2.0 \mathrm{~mL})$, and a stirring bar, subsequently the $\mathrm{N}_{2}$-atmosphere was replaced by $\mathrm{N}_{2} \mathrm{O}$ and the mixture was stirred for 5 minutes. From a stock solution $(0.01 \mathrm{M})$ of precatalyst $1 \mathbf{d}(0.1 \mathrm{~mol} \%) 0.1 \mathrm{~mL}$ were transferred via a syringe into the tube containing the Grignard reagent. The tube was sealed and the mixture was stirred for 5 minutes at room temperature. After the reaction was completed an aliquot was taken and diluted in dichloromethane, the yields were determined by GC-MS analysis applying n-dodecane as internal standard. 4: MS (EI) $\mathrm{m} / \mathrm{z}=214(100$, M+), 200 (12), 199 (84), 171 (29), 156 (9), 128 (18). 13a: MS (EI) $\mathrm{m} / \mathrm{z}=246(100, \mathrm{M}+), 231$ (82), 216 (15), 184 (24), 171 (11), 152 (24), 139 (19), 123 (17). 14a: MS (EI) $\mathrm{m} / \mathrm{z}=154$ (100, M+), 153 (38), 152 (27), 77 (10), 76 (21). 17a: MS (EI) m/z = $198(1, \mathrm{M}+), 85$ (36), 71 (61), 57 (100). 18: MS (EI) $\mathrm{m} / \mathrm{z}=184(100, M+), 169$ (46), 141 (38), 115 (31). 20: $\mathrm{MS}(\mathrm{EI}) \mathrm{m} / \mathrm{z}=230$ (100, M+), 215 (87), 187 (23), 172 (23), 139 (27), 128 (11), 115 (23), 63 (16). 21a: MS (EI) $\mathrm{m} / \mathrm{z}=166(1, \mathrm{M}+), 82(100), 67$ (61), 55 (72). 22: MS (EI) $\mathrm{m} / \mathrm{z}=190$ (27, M+), 147 (69), 134 (29), 121 (69), 103 (15), 91 (100), 89 (12), 77 (46), 65 (40). 23: MS (EI) $\mathrm{m} / \mathrm{z}=206$ (1, M+), 121 (100), 91 (15), 77 (15). 24: MS (EI) m/z = $182(1, \mathrm{M}+), 83$ (100), 67 (30), 55 (95).

[17] For calculation of the turnover frequency the yield after 5 min was taken into account.

[18] K. D. Collins, F. Glorius, Acc. Chem. Res. 2015, DOI: $10.1021 / a r 500434 f$.

[19] C. I. Someya, M. Weidauer, S. Enthaler, Catal. Lett. 2013, 143, 424. 